\title{
Carrier-microencapsulation using Al-catecholate complex to suppress arsenopyrite oxidation: Evaluation of the coating stability under simulated weathering conditions
}

\author{
Kensuke Seno ${ }^{1,}$, Ilhwan Park $^{1}$, Carlito Tabelin ${ }^{2}$, Kagehiro Magaribuchi ${ }^{1}$, Mayumi Ito $^{2}$ and Naoki Hiroyoshi ${ }^{2}$ \\ ${ }^{1}$ Division of Sustainable Resources Engineering, Graduate School of Engineering, Hokkaido University, Japan \\ ${ }^{2}$ Division of Sustainable Resources Engineering, Faculty of Engineering, Hokkaido University, Japan
}

\begin{abstract}
Arsenopyrite (FeAsS) is the most common primary arsenic-sulfide mineral in nature, and its oxidation causes the release of toxic arsenic (As). To mitigate these problems, carrier-microencapsulation (CME), a technique that passivates sulfide minerals by covering their surfaces with a protective coating, has been developed. In the previous study of authors on CME, Al-catecholate complex significantly suppressed arsenopyrite oxidation via electron donating effects of the complex and the formation of an Aloxyhydroxide coating. For the application of this technique to real tailings, however, further study should be carried out to elucidate long-term effectiveness of the coating to suppress arsenopyrite oxidation. This study investigates the stability of the coating formed on arsenopyrite by Al-based CME using weathering tests. The Al-oxyhydroxide coating suppressed arsenopyrite oxidation until about 50 days of the experiment, but after this, the amounts of oxidation products like dissolved $\mathrm{S}$ and As increased due to the gradual dissolution of the coating with time as a result of the low $\mathrm{pH}$ of leachate. This suggests that co-disposal of Al-based CME-treated arsenopyrite with minerals that have appropriate neutralization potentials, so that the $\mathrm{pH}$ is maintained at around 5 to 8 where Al-oxyhydroxide is stable.
\end{abstract}

\section{Introduction}

Mining, mineral processing, and extractive metallurgy generate huge amounts of tailings containing sulfide minerals like pyrite $\left(\mathrm{FeS}_{2}\right)$ and arsenopyrite $(\mathrm{FeAsS})$, which are discharged into tailings ponds or dams. Under atmospheric conditions, sulfide minerals in the tailings are readily oxidized when exposed to oxygen $\left(\mathrm{O}_{2}\right)$ and water, resulting in the formation of acid mine drainage (AMD), one of the most undesirable consequences of mining activities due to its serious negative impacts to the surrounding environment [1]. Among the sulfide minerals, arsenopyrite is particularly notorious because its dissolution not only generates acidity but also releases arsenic (As), a toxic element known to increase the risks of developing numerous diseases like hyperpigmentation, keratosis, anemia, neuropathy, and several types of cancers even at minute amounts $[2,3]$.

Carrier-microencapsulation (CME) has been developed by the authors to prevent the generation of AMD. This technique has also been shown to limit As release from arsenopyrite in batch leaching experiments. In CME, the first step is the formation of soluble complexes between a metal (loid) ion (e.g., $\mathrm{Al}^{3+}$ and $\mathrm{Ti}^{4+}$ ) and a redox-sensitive organic carrier (e.g., catechol, 1,2-dihydroxybenzene, $\left.\mathrm{C}_{6} \mathrm{H}_{4}(\mathrm{OH})_{2}\right)$. The metalcatecholate complex decomposes on the surface of sulfide minerals that dissolve electrochemically. Finally, metal ions freed from the complex precipitate and form a protective coating on the mineral surface limiting the access of oxidants (i.e., $\mathrm{O}_{2}$ and ferric ion) [2-4].

Although it has been shown that CME using Alcatecholate complex (i.e., Al-based CME) could coat arsenopyrite with a protective layer and suppress its oxidation, stability of the coating once exposed to the environment for a long time is still unknown. This study examines the behaviors of the coating under simulated weathering conditions. In the simulated weathering tests, the arsenopyrite sample was repetitively leached with deionized (DI) water at fixed intervals, and the leachates were analyzed with inductively coupled plasma atomic emission spectrometer (ICP-AES). After the weathering test, the samples were analyzed with surface sensitive techniques like scanning electron microscopy with energy dispersive X-ray spectroscopy (SEM-EDX) and diffuse reflectance infrared Fourier transform (DRIFT) spectroscopy, to observe how the coating changed with time.

\section{Materials and methods}

\subsection{Arsenopyrite sample}

The arsenopyrite sample used in this study was obtained from Toroku mine, Miyazaki, Japan. It was crushed by a jaw crusher (BB 51, Retsch Inc. Germany), ground with a disk mill (RS 100, Retsch Inc., Germany), and

Corresponding author: kensuke.seno@gmail.com 
screened to obtain a size fraction between 106 and 150 $\mu \mathrm{m}$. Before the CME treatment, slime coating and any oxidized species were removed from the sample according to the washing method of McKibben et al. [5].

\subsection{Weathering tests}

Two types of solutions were prepared at $\mathrm{pH}$ 5: (1) Alcatechol solution $\left(15 \mathrm{mM} \mathrm{AlCl}{ }_{3} \cdot 6 \mathrm{H}_{2} \mathrm{O}\right.$ and $15 \mathrm{mM}$ catechol) and (2) control (45 mM NaCl). Five grams of washed sample and $50 \mathrm{ml}$ of each of these two prepared solutions were put into a $200 \mathrm{ml}$ Erlenmeyer flask and shaken in a constant temperature water bath $\left(25^{\circ} \mathrm{C}\right)$ at $120 \mathrm{~min}^{-1}$. After 10 days, the residues were collected, washed thoroughly with DI water, and dried in a vacuum oven for 1 day prior to the weathering tests. The weathering test method was based on the procedure used by Bouzahzah et al. [6]; that is, treated samples were placed on 50-mm diameter Büchner funnels with a 0.2 $\mu \mathrm{m}$ membrane filter connected to a centrifuge tube (Fig. 1), and a 7-day leaching cycle was followed consisting of leaching with DI water on the 1st day, followed by 2 days of exposure to ambient conditions, then leaching again on the 4th day followed by an additional 3 days of exposure to the air. The amount of sample placed in the weathering cells and the volume DI water poured were $3 \mathrm{~g}$ and $10 \mathrm{ml}$, respectively. The samples were leached for 3 hours at a fixed time of the day. After this, the leachates were collected using a vacuum pump and then analyzed by ICP-AES (ICPE-9820, Shimadzu Corporation, Japan). After 7 weeks of the weathering tests, the residues were analyzed using SEM-EDX (SSX550, Shimadzu Corporation, Japan) and DRIFT (FT/IR6200HFV with DR PR0410-M attachment, Jasco Analytical Instruments, Japan).

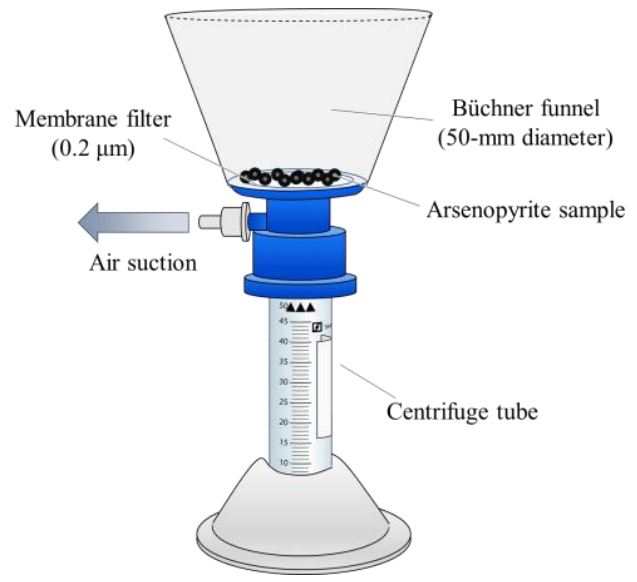

Fig. 1. Set-up of weathering tests.

\section{Results and discussion}

\subsection{Al-based CME treatment}

As shown in Fig. 2(a)-(c), arsenopyrite was extensively oxidized in the control (e.g., $\mathrm{NaCl}$ solution) and after 10 days of treatment, the concentrations of dissolved iron $(\mathrm{Fe}), \mathrm{As}$, and sulfur $(\mathrm{S})$ were reached at ca. 140, 530, and
$350 \mathrm{mg} / \mathrm{L}$, respectively. In the presence of Alcatecholate complex, however, the extent of arsenopyrite oxidation was significantly suppressed. Compared with the control, Al-based CME could suppress the release of Fe, As, and S by 99, 86, and 91\%, respectively (Fig. 2(a)-(c)). Moreover, dissolved $\mathrm{Al}$ concentration decreased with time (Fig. 2(d)). According to the SEMEDX results (Fig. 3), Al was present on the surface of arsenopyrite and the DRIFT spectra show that Al exist most likely as Al-oxyhydroxide (Fig. 4, Table 1). These results implied that the arsenopyrite sample in Al-based CME was covered with Al-oxyhydroxide, which suppressed the oxidation of arsenopyrite.
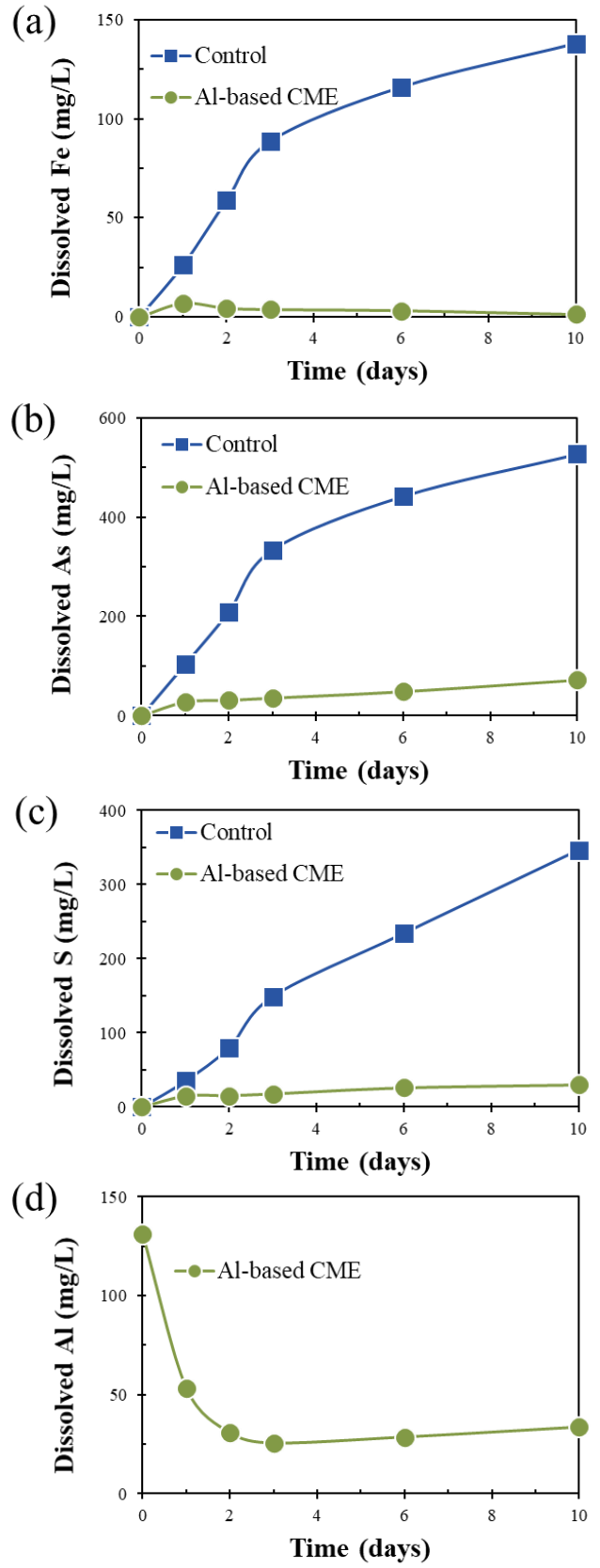

Fig. 2. Leaching of arsenopyrite in control and Al-catecholate complex solution: changes in the concentration of (a) Fe, (b) As, (c) $\mathrm{S}$ and $\mathrm{Al}$ (d) with time. This figure was modified with permission from Chemosphere [3]. 


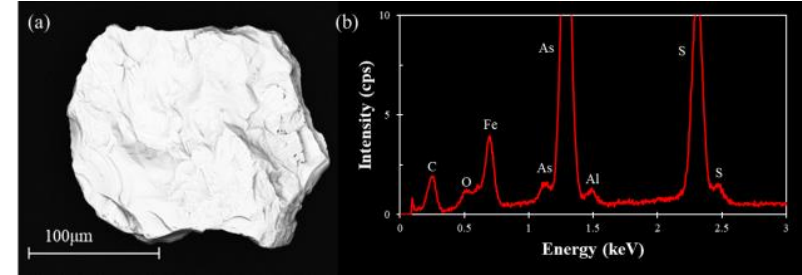

Fig. 3. SEM-EDX analysis of arsenopyrite leached in Alcatecholate complex solution: (a) SEM photomicrograph, (b) EDX spectrum of the scanned area. This figure was modified with permission from Chemosphere [3].

\subsection{Weathering tests}

Fig. 5(a)-(c) illustrates the cumulative amounts of Fe, As, and $\mathrm{S}$ released from the weathering tests, and the results showed that the oxidation of CME-treated arsenopyrite was less extensive compared with that of the control. However, the cumulative concentrations of $\mathrm{Fe}$, As, and $\mathrm{S}$ in Al-based CME increased gradually, which suggest that the Al-oxyhydroxide coatings formed by Al-based CME treatment were dissolved with time. Based on thermodynamic considerations (Fig. 6), the Aloxyhydroxide coating formed during Al-based CME treatment was most likely boehmite $(\gamma-\mathrm{AlO}(\mathrm{OH}))$, which could be dissolved under acidic conditions (i.e., below $\mathrm{pH}$ 4.5). At the beginning of the weathering tests, the leachate $\mathrm{pH}$ of Al-based CME treated sample was around $\mathrm{pH} 4.5$ (Fig. 5(d)), so the coating might have dissolved as $\mathrm{pH}$ decreased with time. This deduction is further supported not only by the non-existent signal of Al from the SEM-EDX analysis of the sample treated with Al-based CME after the weathering tests (Fig. 3 and Fig. 7) but also of the absence of Al-related bonds in the DRIFT spectrum (Fig. 4(b)). Nonetheless, Al-based CME treatment effectively suppressed arsenopyrite oxidation for up to 50 days as was observed in Fig. 4 and 7. The surface of arsenopyrite treated by Al-based CME was also less oxidized than the untreated sample. As shown in the SEM photomicrographs of the control (Fig. 5(a)), secondary minerals, most likely Fe-oxyhydroxide and/or ferric arsenate, were substantially formed on the surface of arsenopyrite, and its EDX spectrum (Fig. 5(d)) shows strong signal of O. Moreover, DRIFT spectrum (Fig. 4(a)) of the control after the weathering test exhibits higher peaks of the two products of arsenopyrite oxidation compared with that treated by Albased CME: stretching band of $\mathrm{O}-\mathrm{H}$ coordinated with $\mathrm{Fe}^{3+}$ at $722 \mathrm{~cm}^{-1}$ and vibration of arsenate at $786 \mathrm{~cm}^{-1}[8-$ $10]$.

Table 1. Assignments of Al-related absorption bands from the DRIFT spectra of arsenopyrite leached in control and Alcatecholate complex solution [7].

\begin{tabular}{ll}
\hline Wavenumber $\left(\mathbf{c m}^{-1}\right)$ & Assignment \\
\hline \hline 834,745 & $\mathrm{Al}=\mathrm{O}$ bending vibrations \\
668,600 & Angle bending vibrations of $\mathrm{AlO}(\mathrm{OH})$ \\
$569,494,479$ & Angle deformations of $\mathrm{AlO}(\mathrm{OH})$ \\
\hline
\end{tabular}

(a)

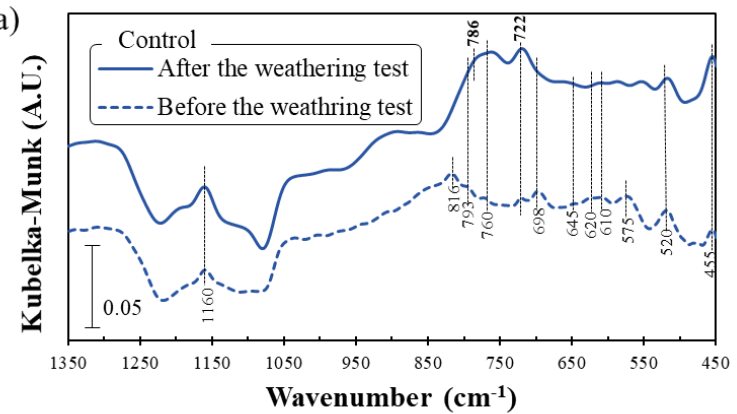

(b)

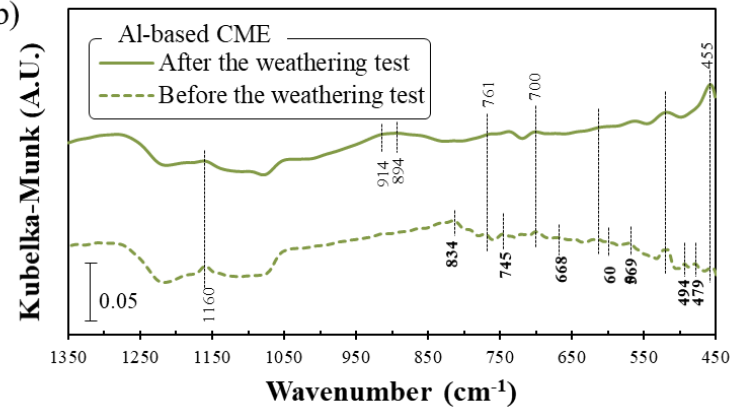

Fig. 4. DRIFT spectra of arsenopyrite (a) leached in control weathering test.

(a)

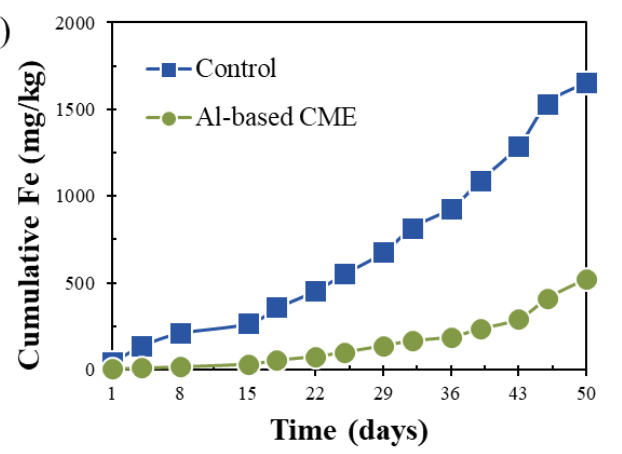

(b)

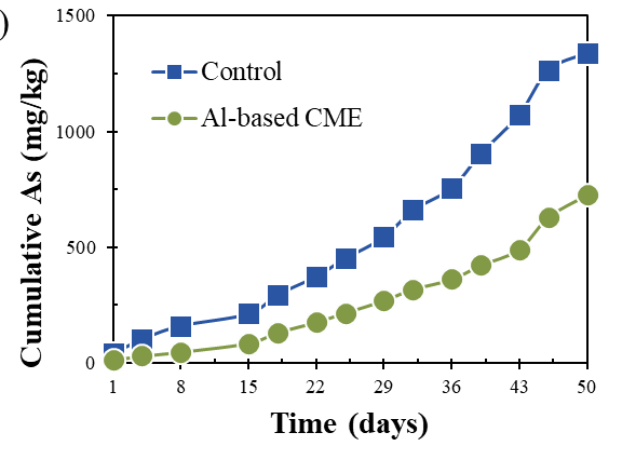

(c)

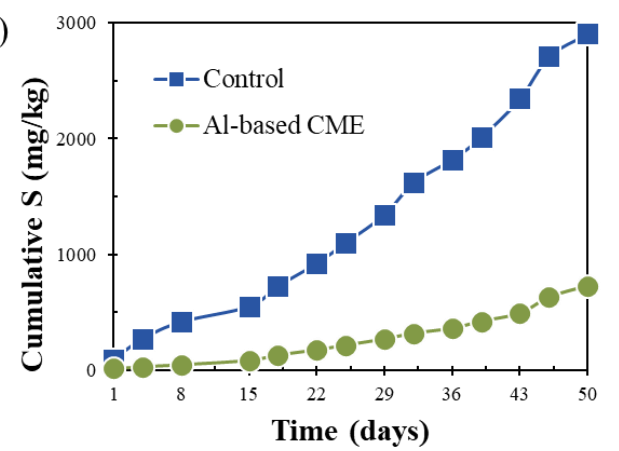

Fig. 5 (a-c). The cumulative (a) Fe, (b) As and (c) S release with time from the weathering tests on arsenopyrite preleached in control and Al-catecholate. 
(d)

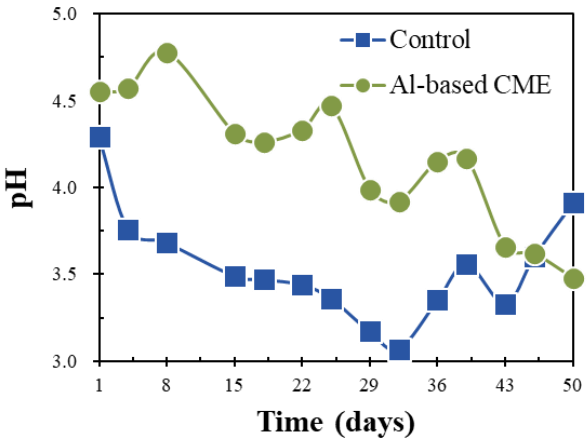

Fig. 5 (d). The evolution of $\mathrm{pH}$ from the weathering tests on arsenopyrite pre-leached in control and Al-catecholate.

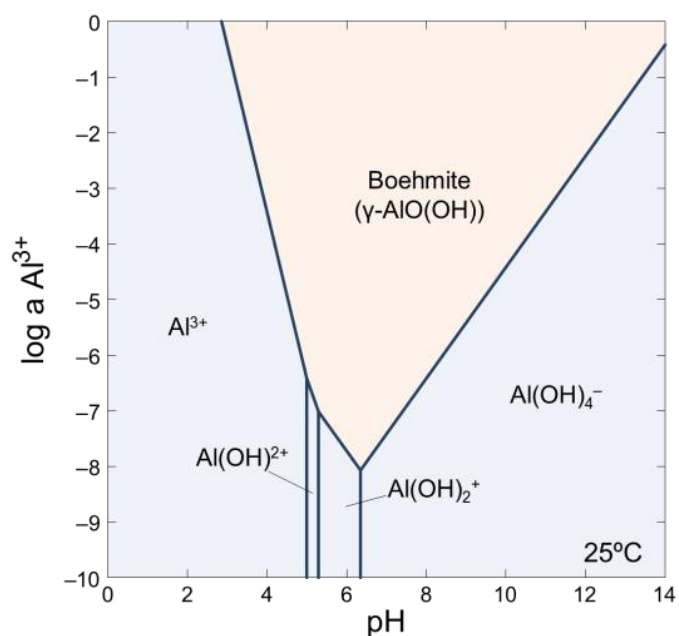

Fig. 6. The equilibrium Log activity-pH diagram of $\mathrm{Al}^{3+}-\mathrm{H}_{2} \mathrm{O}$ system at $25^{\circ} \mathrm{C}$ and 1.013 bar.

\section{Conclusion}

This study investigated the stability of Al-based CME treated arsenopyrite under simulated weathering conditions. The Al-oxyhydroxide coating was most likely dissolved as $\mathrm{pH}$ decreased, but it still effectively suppressed arsenopyrite oxidation for up to 50 days. To improve the effectiveness of Al-oxyhydroxide coating on the suppression of arsenopyrite oxidation, the authors suggest the co-disposal of CME-treated arsenopyrite with minerals (e.g., limestone $\left(\mathrm{CaCO}_{3}\right)$, dolomite $\left(\mathrm{CaMg}\left(\mathrm{CO}_{3}\right)_{2}\right)$, and apatite $\left.\left(\mathrm{Ca}_{10}\left(\mathrm{PO}_{4}\right)_{6}(\mathrm{OH})_{2}\right)\right)$ and industrial by-products (e.g., cement kiln dust (CKD) and pulp/paper residue) that have appropriate neutralization potential to maintain the $\mathrm{pH}$ at around 5 to 8 where Aloxyhydroxide is stable.

This study was financially supported by the Japan Society for the Promotion of Science (JSPS) grant-in-aid for Scientific research (KAKENHI) (Grant numbers: JP17H03503 and JP17K12831).

\section{References}

[1] Rimstidt, J.D. and Vaughan, D.J. Pyrite oxidation: A state-of-the-art assessment of the reaction mechanism, Geochimica et Cosmochimica Acta, 67(5), 2003, 873-880.
[2] Park, I., Tabelin, C.B., Seno, K., Jeon, S., Ito, M., Hiroyoshi, N. Simultaneous suppression of acid mine drainage formation and arsenic release by Carrier-microencapsulation using aluminumcatecholate complexes, Chemosphere, 205, 2018, 414-425.

[3] Park, I., Tabelin, C. B., Magaribuchi, K., Seno, K., Ito, M., Hiroyoshi, N. Suppression of the release of arsenic from arsenopyrite by carriermicroencapsulation using Ti-catechol complex, Journal of Hazardous Materials, 344, 2018, 322332.

[4] Satur, J., Hiroyoshi, N., Tsunekawa, M., Ito, M., Okamoto, H. Carrier-microencapsulation for preventing pyrite oxidation, ScienceDirect, 83, 2007, 116-124.

[5] McKibben, M. A., Tallant, B. A., del Angel, J. K. Kinetics of inorganic arsenopyrite oxidation in acidic aqueous solutions, Applied Geochemistry, 23, 2008, 121-135

[6] Bouzahzah, H., Benzaazoua, M., Bussiere, B., Plante, B. Prediction of Acid Mine Drainage: Importance of Mineralogy and the Test Protocols for Static and Kinetic Tests, Mine Water Environ, 33, 2014, 54-65.

[7] Ram, S. Infrared spectral study of molecular vibration in amorphous, nanocrystalline and $\mathrm{AlO}(\mathrm{OH}) \alpha \mathrm{H} 2 \mathrm{O}$ bulk crystals, Infrared Phys. Technol. 42, 2001,547-560.

[8] Tabelin, C.B., Veerawattananun, S., Ito, M., Hiroyoshi, N., Igarashi, T. Pyrite oxidation in the presence of hematite and alumina: I. Batch leaching experiments and kinetic modeling calculations, Sci. Total Environ, 580, 2017, 687-698.

[9] Tabelin, C.B., Veerawattananun, S., Ito, M., Hiroyoshi, N., Igarashi, T. Pyrite oxidation in the presence of hematite and alumina: II. Effects on the cathodic and anodic half-cell reactions, Sci. Total Environ, 581-582, 2017, 126-135.

[10] Achimovičová, M., Baláž, P. Influence of mechanical activation on selectivity of acid leaching of arsenopyrite, Hydrometallurgy, 77(1-2), 2005, 3-7 